\title{
Active Oxygen Monitor Using Quartz Crystal Microbalance Method with Polymer Detection Layers
}

\author{
Hiroyuki Matsumoto, Mikihiko Matsuoka, Tatsuyuki Iwasaki, \\ Shinobu Kinoshita, Satoru Iwamori ${ }^{\dagger}$ and Kazutoshi Noda ${ }^{\ddagger}$ \\ Corporate Advanced Technology, Iwasaki Electric Co., Ltd., \\ 1-20 Fujimicho, Gyoda, Saitama 361-0021, Japan \\ ${ }^{\dagger}$ Graduate School of Natural Science and Technology, Kanazawa University \\ Kakuma-machi, Kanazawa, Ishikawa 920-1192, Japan \\ * Institute for Environmental Management Technology, \\ National Institute of Advanced Institute of Standard and Technology (AIST) \\ Onogawa, Tsukuba, Ibaraki 305-8569, Japan
}

\begin{abstract}
A novel trial based on a quartz crystal microbalance (QCM) sensor with various polymer thin-films prepared by physical deposition methods was undertaken to realize a quantification monitor for the active oxygen that is generated under surface treatment processes. Active oxygen, specifically atomic oxygen radicals under inductively coupled oxygen plasma, was successfully monitored using the polytetrafluoroethylene (PTFE), polyimide, and carbon coated QCM. This study also discusses the optical emission spectroscopy of the oxygen plasma and the distribution of atomic oxygen radicals inside the process chamber using a numerical simulation.
\end{abstract}

Keywords: active oxygen, quartz crystal microbalance, polymer thin film

\section{Introduction}

The need to reduce greenhouse gas emissions (e.g., the fluorocarbons used in semiconductor manufacturing processes) has meant that the use of active oxygen is attracting more attention. Active oxygen, generated by methods employing ultraviolet lamps and discharge plasma, plays an important role in several industrial processes including surface cleaning, surface modification, sterilization, and oxidation. These processes demand precise reproducibility to provide a high production yield. Therefore, the ability to monitor the amount of atomic oxygen accurately with a reasonable monitor system is critical to the precise control of these processes. With a view to meeting these demands, we focused on the quartz crystal microbalance (QCM) method as a candidate for realizing an active oxygen monitor. A QCM is a sensor device that is capable of the nanogram-order measurement of changes in mass on the surface of a quartz crystal by observing shifts in the resonant frequency. Hence, this method can be applied to gas sensing applications by selecting the appropriate electrode material for the detection layer on the quartz crystal. [1] We investigated the characteristics of active oxygen monitoring using a QCM with silver, carbon, and carbon/silver thin-film detection layers [2],[3]. However, these layers did not meet our requirements, especially in terms of finding practical processes for long duration monitoring. Therefore, we verified the point aimed at long-duration active oxygen monitoring with high precision using a sputter-coated polymer, such as polytetrafluoroethylene (PTFE) and polyimide, which are polymers that exhibit relatively low reaction efficiencies in relation to active oxygen [4]. We first evaluate the active oxygen species in the oxygen plasma with a spectroscopic survey and a numerical study. Then we reveal the sensing properties of the polymer- coated QCM.

\section{Method}

2.1 Principle of QCM 
A QCM is a sensor device that makes it possible to measure nanogram-order mass changes on a quartz crystal plate surface as a frequency shift. The frequency shift is expressed by the Sauerbrey's equation as follows [5],

$$
\Delta f=-2 \Delta m n f_{0}^{2} /\left(A \mu_{q}^{1 / 2} \rho_{q}^{1 / 2}\right)
$$

where $f_{0}$ is the resonant frequency, $\Delta f$ is the frequency shift, $\Delta m$ is the mass change in QCM caused by adsorption or desorption on the electrode, $n$ is the harmonic number, $A$ is the area of the electrode coated on the crystal, $\mu_{q}$ is the elastic coefficient $\left(2.947 \times 10^{13} \mathrm{~g} \mathrm{~m}^{-1} \mathrm{~s}^{-2}\right)$, and $\rho$ ${ }_{q}$ is the crystal density $\left(2.648 \mathrm{~g} \mathrm{~cm}^{-3}\right)$. In this study, we used a commercially available standard AT- cut quartz crystal sensor with gold electrodes, a diameter of $14 \mathrm{~mm}$ and a resonant frequency of $6 \mathrm{MHz}$. With a view to future mass production, the PTFE and polyimide films were coated on one side of a quartz crystal using the RF sputtering method. The film preparation procedure was as follows. A quartz crystal plate was mounted on a stainless steel substrate holder in sputtering equipment (SBR-1104E, ULVAC). A sputtering target, made of PTFE (Teflon ${ }^{(B)}$ ) or polyimide film (Upilex-S ${ }^{(\mathbb{R})}$, Ubekousan), was mounted on a metal backing plate opposite the substrate. The distance between the target and the substrate was about $40 \mathrm{~mm}$. The equipment was evacuated to less than $6.7 \times 10^{-3} \mathrm{~Pa}$, and then argon (Ar) gas was introduced at $5.3 \times 10^{-1} \mathrm{~Pa}$. The applied RF (13.56 MHz) power between the target and the substrate holder was set at $100 \mathrm{~W}$ to the PTFE and $150 \mathrm{~W}$ to the polyimide. The obtained film thickness was about $30 \mathrm{~nm}$ for PTFE and about $75 \mathrm{~nm}$ for polyimide with an 8 $\mathrm{mm}$ diameter area. The size is that of the detection window of the QCM sensor head. For comparison, carbon film was coated on a crystal with a flash deposition method based on the resistive heating of a pair of carbon rods. The obtained carbon film thickness was about $50 \mathrm{~nm}$. Fig. 1 shows the appearance of each QCM. The polymer sputter coating method is described in detail in refs. [6] and [7].

\subsection{Active Oxygen Source (Experimental Setup)}

To confirm the appropriateness of active oxygen monitoring using QCM sensors with a polymer layer, we selected inductively coupled plasma (ICP) as an active oxygen source. The experimental setup is shown in Fig. 2. The process chamber was made of stainless steel and its inner diameter and height were 150 and 130 $\mathrm{mm}$, respectively. The ICP source was loaded in the top part of the chamber, which consisted of a Pyrex glass tube with an external diameter of 70 $\mathrm{mm}, 2 \mathrm{~mm}$ thick, $140 \mathrm{~mm}$ height, and a 4-turn water-cooled copper tube was wound around the perimeter of the glass tube. To prevent RF noise and ionized gas diffusion, the ICP source and the process chamber were separated by using an electrically grounded expanded metal mesh with a $1 \mathrm{~mm}$ diameter aperture. After evacuating the vacuum chamber to below $10^{-1} \mathrm{~Pa}$ using a rotary pumping system, oxygen gas was introduced at a constant flow rate into the vacuum chamber from the top part of the ICP source. Subsequently, RF (13.56 MHz) power was fed to the copper tube (RF coil) through the matching network, and then inductively coupled oxygen plasma was generated inside the glass tube. A quartz crystal with a polymer thin film was inserted into the QCM sensor head fixed on the substrate holder (Fig. 3) at a position $35 \mathrm{~mm}$ below the ICP source and on the central axis of the equipment and then connected to the oscillation circuit.

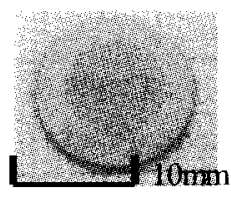

(a)

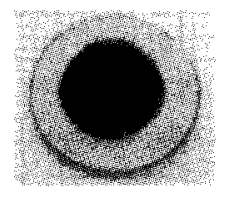

(b)

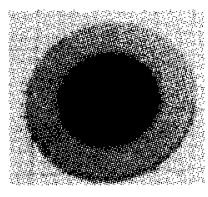

(c)
Figure. 1 Quartz crystal with polymer layer (1. to r.) PTFE, polyimide and carbon)

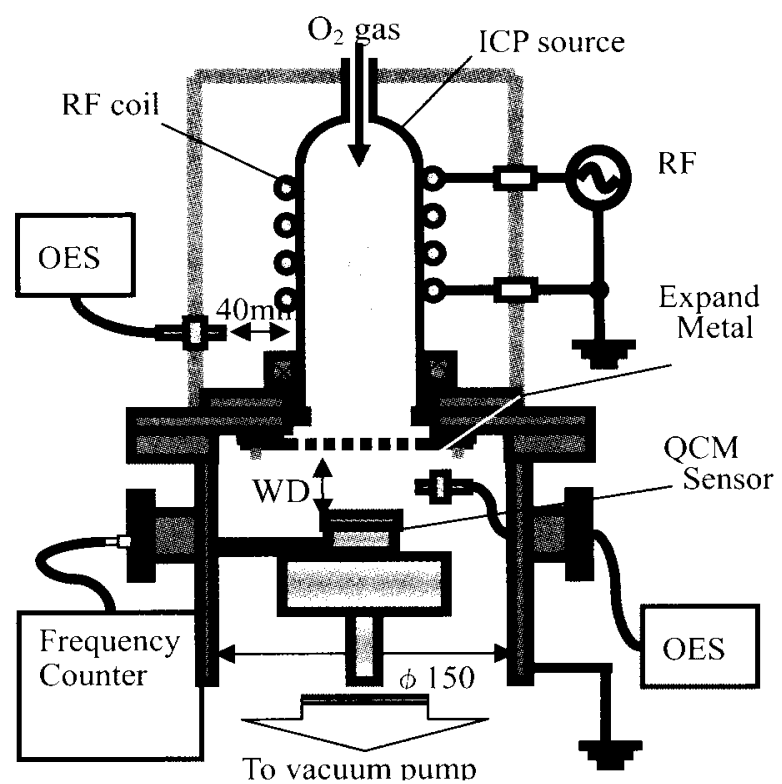

Figure. 2 Experimental setup of process chamber with ICP source 


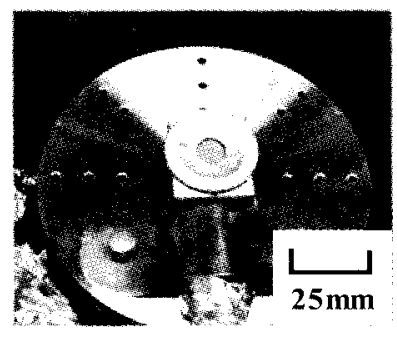

Figure. 3 QCM sensor head fixed on substrate holder

To prevent the thermal drift of the QCM, the temperature of the sensor head (stainless steel) was maintained at $20^{\circ} \mathrm{C}$ by circulating water. Frequency shifts during plasma generation were monitored every $30 \mathrm{sec}$ for $25 \mathrm{~min}$ with a frequency counter (SC-7205, Iwatsu), and the results were recorded.

\subsection{Optical Emission Spectroscopy}

Optical emission spectroscopy (OES) was used to confirm the kind of active oxygen species that were generated in the oxygen plasma.

An OES system (USB2000, Ocean Optics Inc.) with a measurement wavelength range of 250 to $850 \mathrm{~nm}$ and a wavelength resolution of 1 $\mathrm{nm}$ was used in this study. The distance between the perimeter of the ICP glass tube and the edge of the optical fiber (numerical aperture 0.22) without any optical lens was $45 \mathrm{~mm}$, as shown in Fig. 2. Moreover, we also performed a direct observation inside the process chamber, namely after the glow region, using an extended optical fiber. Then, the distance between the ICP source and the fiber edge was set in the 15 to $65 \mathrm{~mm}$ range.

\subsection{Numerical Study of ICP}

It is difficult to obtain accurate information regarding the spatial distribution of the plasma parameters (e.g., electron temperature, electron density, and generated active oxygen quantity) inside all over the process chamber. Therefore, we undertook a numerical study of the ICP (oxygen plasma), to confirm whether or not active oxygen species were present near the QCM sensor. We performed simulations using the direct simulation Monte Carlo method (DSMCM) and the electron Monte Carlo simulation method (EMCSM) with the "PEGASUS" software. The calculation methods are described in detail elsewhere [8]-[14].

The calculation model and geometries were the same as those of the experimental set up (Fig. 2).
Table. 1 Reactions considered in this work

\begin{tabular}{|c|c|}
\hline Reaction & References \\
\hline $\mathrm{e}+\mathrm{O} \rightarrow \mathrm{O}+\mathrm{e}$ & [15] \\
\hline $\mathrm{e}+\mathrm{O} \rightarrow \mathrm{O}\left({ }^{1} \mathrm{D}\right)+\mathrm{e}$ & [16] \\
\hline$e+O \rightarrow O\left({ }^{1} S\right)+e$ & [16] \\
\hline $\mathrm{e}+\mathrm{O} \rightarrow \mathrm{O}^{+}+\mathrm{e}+\mathrm{e}$ & [16] \\
\hline $\mathrm{O}^{-}+\mathrm{O} \rightarrow \mathrm{O}_{2}^{+}+\mathrm{e}$ & [17] \\
\hline $\mathrm{e}+\mathrm{O}^{-} \rightarrow \mathrm{O}+\mathrm{e}+\mathrm{e}$ & [17] \\
\hline $\mathrm{e}+\mathrm{O}_{2} \rightarrow \mathrm{O}^{+}+\mathrm{O}^{-}$ & [17] \\
\hline $\mathrm{e}+\mathrm{O}_{2} \rightarrow \mathrm{O}\left({ }^{1} \mathrm{D}\right)+\mathrm{O}\left({ }^{\mathrm{l}} \mathrm{D}\right)+\mathrm{e}$ & [17] \\
\hline $\mathrm{e}+\mathrm{O}_{2} \rightarrow \mathrm{O}\left({ }^{3} \mathrm{P}\right)+\mathrm{O}\left({ }^{1} \mathrm{D}\right)+\mathrm{e}$ & {$[17]$} \\
\hline $\mathrm{e}+\mathrm{O}_{2} \rightarrow \mathrm{O}\left({ }^{3} \mathrm{P}\right)+\mathrm{O}\left({ }^{3} \mathrm{P}\right)+\mathrm{e}$ & [17] \\
\hline $\mathrm{e}+\mathrm{O}_{2} \rightarrow \mathrm{O}+\mathrm{O}\left({ }^{3} \mathrm{P}\right)+\mathrm{e}$ & {$[17]$} \\
\hline $\mathrm{e}+\mathrm{O}_{2} \rightarrow \mathrm{O}_{2}^{+}+\mathrm{e}+\mathrm{e}$ & [17] \\
\hline $\mathrm{e}+\mathrm{O}_{2} \rightarrow \mathrm{O}_{2}\left(\mathrm{a}^{\prime} \Delta \mathrm{g}\right)+\mathrm{e}$ & {$[17]$} \\
\hline $\mathrm{e}+\mathrm{O}_{2} \rightarrow \mathrm{O}_{2}\left(\mathrm{~b}^{1} \sum \mathrm{g}^{+}\right)+\mathrm{e}$ & [17] \\
\hline $\mathrm{e}+\mathrm{O}_{2} \rightarrow \mathrm{O}_{2}\left(\mathrm{c}^{1} \sum \mathrm{u}^{-}-\mathrm{a}^{3} \Sigma \mathrm{g}^{+}\right)+\mathrm{e}$ & [17] \\
\hline $\mathrm{e}+\mathrm{O}_{2} \rightarrow \mathrm{O}_{2}+\mathrm{e}$ & [17] \\
\hline $\mathrm{e}+\mathrm{O}_{2} \rightarrow \mathrm{O}_{2}($ rotation $)+\mathrm{e}$ & [17] \\
\hline $\mathrm{e}+\mathrm{O}_{2} \rightarrow \mathrm{O}_{2}($ vibration- 1$)+\mathrm{e}$ & {$[17]$} \\
\hline $\mathrm{e}+\mathrm{O}_{2} \rightarrow \mathrm{O}_{2}($ vibration-2)+e & {$[17]$} \\
\hline $\mathrm{e}+\mathrm{O}_{2} \rightarrow \mathrm{O}_{2}$ (vibration-3)+e & [17] \\
\hline $\mathrm{e}+\mathrm{O}_{2} \rightarrow \mathrm{O}_{2}$ (vibration-4)+e & [17] \\
\hline $\mathrm{O}^{-}+\mathrm{O}_{2} \rightarrow \mathrm{O}^{-}+\mathrm{O}_{2}$ & [17] \\
\hline $\mathrm{O}^{--}+\mathrm{O}_{2} \rightarrow \mathrm{O}+\mathrm{O}_{2}+\mathrm{e}$ & {$[17]$} \\
\hline $\mathrm{O}+\mathrm{O}_{2} \rightarrow \mathrm{O}+\mathrm{O}_{2}$ & {$[17]$} \\
\hline $\mathrm{O}_{2}^{+}+\mathrm{O}_{2} \rightarrow \mathrm{O}_{2}^{+}+\mathrm{O}_{2}$ & [17] \\
\hline $\mathrm{O}^{-}+\mathrm{O}_{2} \rightarrow \mathrm{O}+\mathrm{O}_{2}$ & [17] \\
\hline $\mathrm{e}+\mathrm{O}_{2}{ }^{+} \rightarrow \mathrm{O}+\mathrm{O}\left({ }^{1} \mathrm{D}\right)$ & {$[17]$} \\
\hline $\mathrm{O}^{-}+\mathrm{O}^{+} \rightarrow 2 \mathrm{O}$ & [18] \\
\hline $\mathrm{O}+\mathrm{O}_{2} \rightarrow \mathrm{O}_{2}{ }^{+}+\mathrm{O}$ & [19] \\
\hline
\end{tabular}

The oxygen gas pressure and RF power were fixed at $10 \mathrm{~Pa}$ and $200 \mathrm{~W}$, respectively. The initial conditions, as regards electron density, electron temperature, and molecular oxygen density, were $10^{15} \mathrm{~m}^{-3}, 3.0 \mathrm{eV}$, and $2.43 \times 10^{21} \mathrm{~m}^{-3}$, respectively. We considered the collisions between electron and oxygen molecules (ground- state, excitation level, and ions) and/ or atomic oxygen $\left({ }^{1} \mathrm{D},{ }^{3} \mathrm{P}\right.$ state), and reactions between oxygen species, as shown Table. 1. We did not consider reactions related to ozone $\left(\mathrm{O}_{3}\right)$ to limit the amount of calculation required. The EMCSM and DSMCM calculation cycles were alternated until a steady state was reached $\left(30 \mathrm{RF}\right.$ cycles, $\left.2.21 \times 10^{-6} \mathrm{sec}\right)$.

\section{Results and Discussion}

3.1 Identification of Active Oxygen by OES 
Fig. 4 shows the optical emission spectra of the oxygen plasma. The oxygen gas pressure ranges from 10 to $150 \mathrm{~Pa}$ and the RF power was set at $200 \mathrm{~W}$. The spectrum contains a prominent peak at $777 \mathrm{~nm}$ emission, which is derived from atomic oxygen radicals $\left(\mathrm{O}^{*},{ }^{1} \mathrm{D}-{ }^{3} \mathrm{P}\right.$ transitions $)$. We confirmed that the $777 \mathrm{~nm}$ intensity increased as the oxygen gas pressure decreased. In contrast, when the gas pressure was increased above $36 \mathrm{~Pa}$, $761 \mathrm{~nm}$ emission corresponding to oxygen molecular radicals $\left(\mathrm{O}_{2}{ }^{*}\right)$ appeared. Then the 761 $\mathrm{nm}$ intensity increased remarkably with decreasing the $777 \mathrm{~nm}$ intensity at a high oxygen gas pressure (above $62 \mathrm{~Pa}$ ). We assumed that the electron or other species in the plasma had insufficient energy to dissociate the oxygen molecules into atomic oxygen (over $5 \mathrm{eV}$ ) at a high oxygen gas pressure.

Fig. 5 shows the emission intensity at a wavelength of $777 \mathrm{~nm}$ (atomic oxygen radicals), measured directly inside the process chamber. In this figure, "WD" means the working distance, which corresponds to the distance between the expanded metal mesh and the acceptance edge of the OES fiber as seen in Fig. 2. The result clearly indicates the existence of atomic oxygen radicals inside the chamber. In other words, atomic oxygen radicals generated inside the ICP source flowed downwards as an "after glow", drawn by the evacuation flow. [20] However, the emission intensity of $777 \mathrm{~nm}$ in the chamber region was less than one hundredth of the value measured for the outside the ICP source, and no $761 \mathrm{~nm}$ emission (oxygen molecule radicals) was observed inside the chamber with this method.

\subsection{Identification of Active Oxygen by Numerical Simulation}

As mentioned above, to discuss reactivity, we used numerical simulations to analyze plasma parameters such as the electron density and temperature, and the charged and neutral particle density (e.g., oxygen radicals...), which plays an important role in maintaining the discharge. The results are shown in Fig. 6. For convenience, the geometry of the equipment used in this calculation is shown only on the right based on the assumption that the plasma parameters are axial symmetric. An electron density of $10^{17} \mathrm{~m}^{-3}$ order was obtained, and we confirmed that the electrons were localized inside the center part of the ICP source (Fig.6 (a)). An electron temperature of about $3.8 \mathrm{eV}$ was also confirmed (Fig. 6 (b)). The

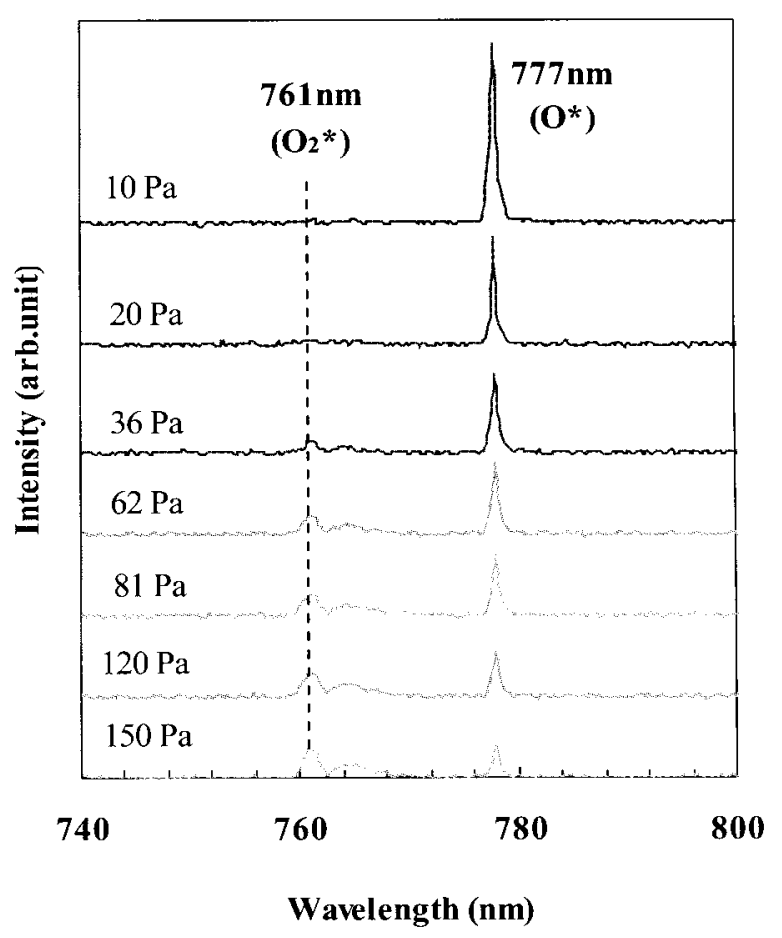

Figure. 4 Optical emission spectra of oxygen plasma under various gas pressures (measurement point: outside ICP source)

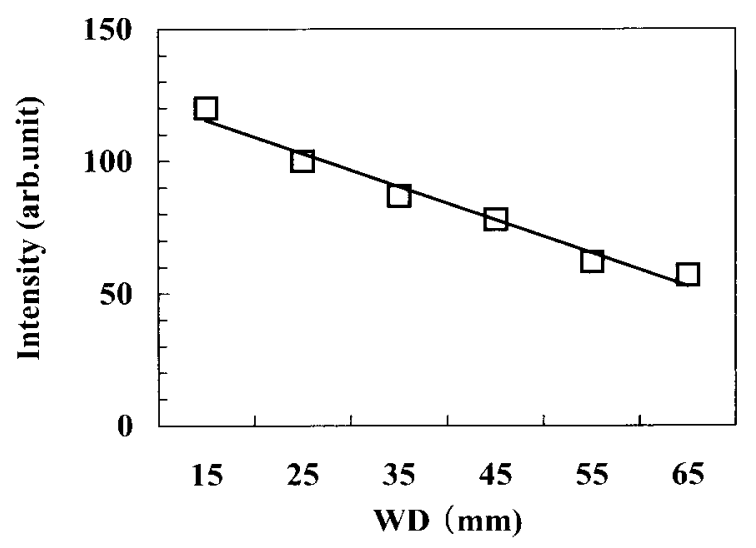

Figure. 5 Emission intensity at $777 \mathrm{~nm}$ (atomic oxygen radical) inside process chamber

spatial distribution of the atomic oxygen densities is shown in Fig. 6 (c). The result indicates that the atomic oxygen (ground state, ${ }^{3} \mathrm{P}$ ), with a density of about $10^{21}$, diffuses uniformly from the ICP source in a downstream direction from the substrate holder. By contrast, we confirmed that charged species such as positive and negative ions $\left(\mathrm{O}^{-}, \mathrm{O}^{+}\right.$, and $\left.\mathrm{O}_{2}{ }^{+}\right)$were generated only inside the ICP source and did not diffuse into the chamber region (Fig. 6 (d), (e), and (f)). 


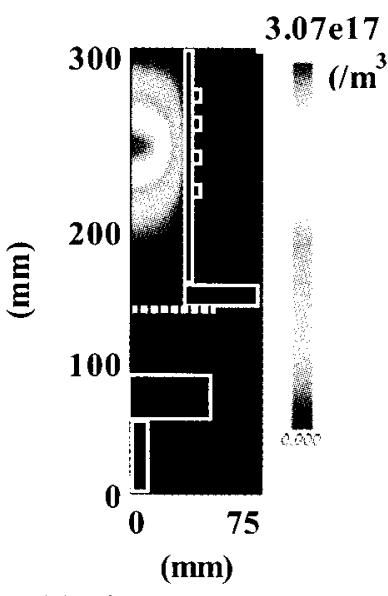

(a) Electron density

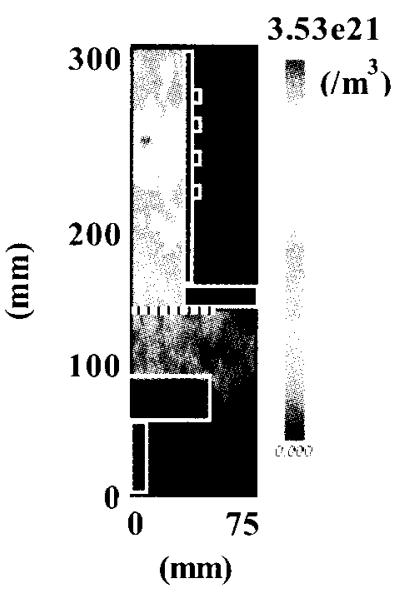

(c) $\mathrm{O}^{*}\left({ }^{3} \mathrm{P}\right)$ density

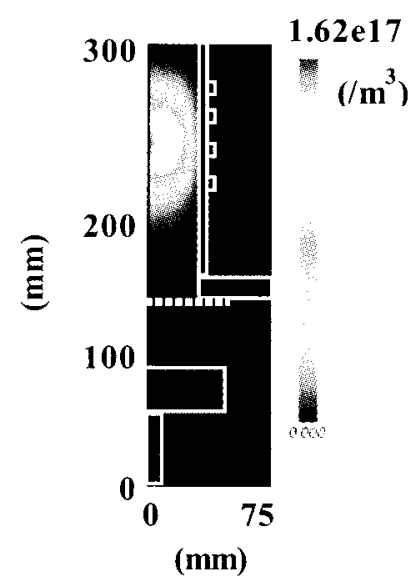

(e) $\mathrm{O}^{+}$density

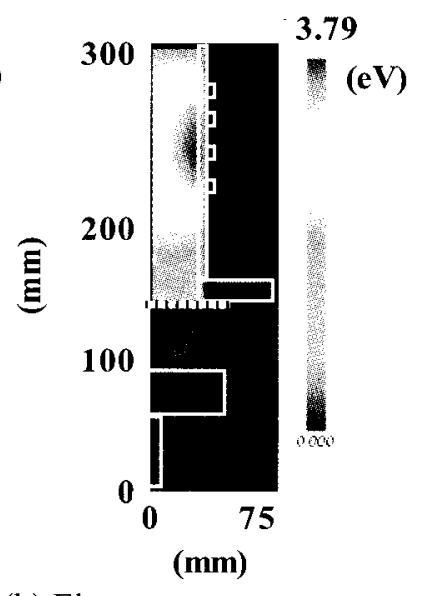

(b) Electron temperature

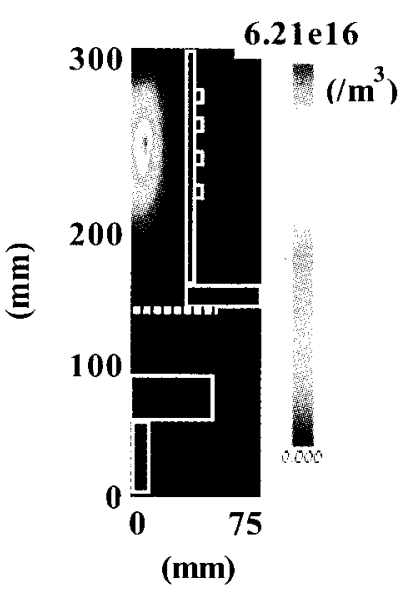

(d) $\mathrm{O}^{-}$density

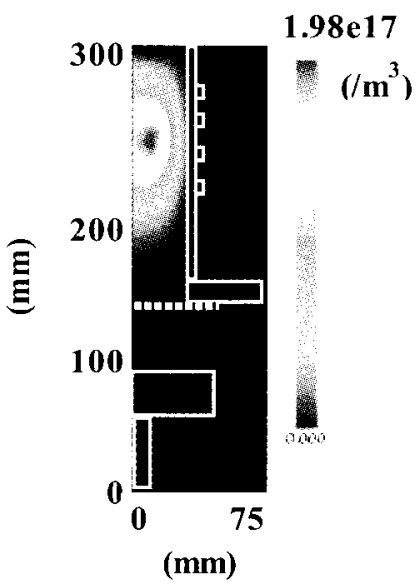

(f) $\mathrm{O}_{2}^{+}$density

Figure. 6 Simulation results for inductively coupled oxygen plasma (Calculating conditions: $\mathrm{O}_{2} 10 \mathrm{~Pa}, \mathrm{RF}$ power of $200 \mathrm{~W}$ fed to 4-turn coil, data are at RF 30 cycles)

We assume that this is because the charged particles in the oxygen plasma are trapped in the discharge region by an effect of the electrically

grounded metal mesh. The density of the ion species was $10^{16}-10^{17} \mathrm{~m}^{-3}$, which is four or five orders less than the atomic oxygen density, because the ion generation yield was originally smaller than that of the low- pressure glow plasma (e.g., $10^{-1}-10^{-2} \mathrm{~Pa}$ ), and ion-ion recombination is frequent under these conditions.

The above led us to conclude that the atomic oxygen radical is the predominant active oxygen species in the process chamber. Hence, the QCM sensor is likely to detect only atomic oxygen at a gas pressure of 10-20 $\mathrm{Pa}$, as mentioned below. We also confirmed that the ground-state oxygen molecules hardly influenced the change in the resonant frequency on the QCM, which means that gas attachment to the polymer surface is negligible in the measurements.

\subsection{Frequency shift of QCM}

Fig. 7 shows the QCM frequency shift results. The results confirm that all the QCM exhibited a frequency increase, i.e., a weight loss during oxygen plasma generation. Therefore, we assumed that the QCM sensor successfully detected the process of polymer degradation owing to the formation of a volatile flux $\left(\mathrm{CO}, \mathrm{CO}_{2}\right)$ by reacting with atomic oxygen, i.e., the polymer coated QCM can be used for atomic oxygen monitoring. The carbon-QCM exhibited a freqency increase of about $20 \mathrm{~Hz}$ in $25 \mathrm{~min}$. The polyimide-QCM exhibited a frequency shift of about $180 \mathrm{~Hz}$. The difference between the frequency increase values of the carbon and polyimide was assumed to derive from the difference between their reaction-efficiencies with respect to atomic oxygen. That is to say, the polyimide-QCM detected not only the carbon desorption caused by the atomic oxygen reaction but the emission of other elements e.g., oxygen, nitrogen, and hydrogen, which are included in the polymer structure. We found that the polyimide-QCM and carbon-QCM were capable of long-duration atomic oxygen sensing, which was one goal of this study.

In contrast, the frequency shift value of the PTFE-QCM was about $600 \mathrm{~Hz}$ in less than 20 min. This result indicates that the PTFE-QCM is suitable for high-resolution sensing. However, the frequency shift result for the PTFE-QCM was not consistent with the result reported by Morton et al [21], which revealed that various bulk polymer films were degraded when irradiated with atomic oxygen. We considered the reason for this 
inconsistency to be the difference between the structures of the bulk materials and the sputter-coated thin films, which do not have a complete polymer structure. Moreover, there is a possibility that atomic fluorine was generated and emitted from the thin-film surface via complex chemical reactions, and accelerated the polymer etching [7] together with atomic oxygen radicals. The verification of these assumptions constitutes our future work.

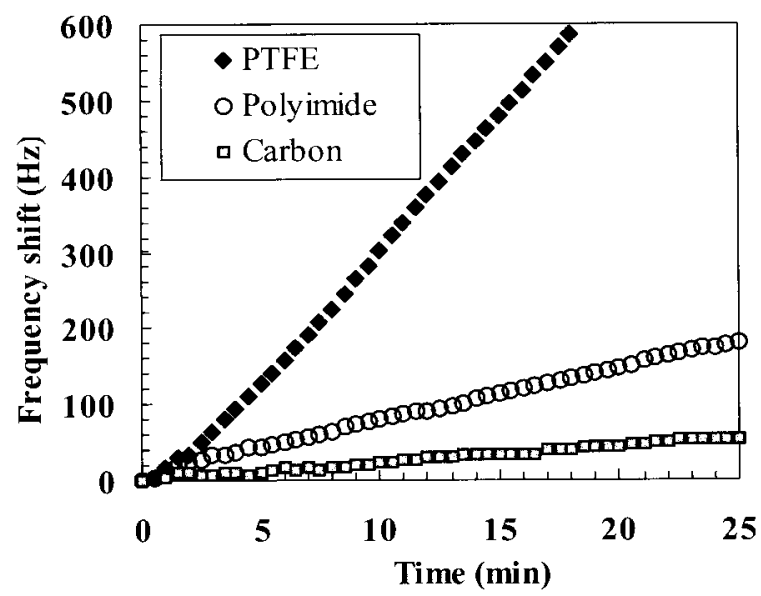

Figure. 7 Frequency shifts of polymer coated QCM $\left(\mathrm{O}_{2} 25 \mathrm{~Pa}, \mathrm{RF} 200 \mathrm{~W}\right.$, WD $\left.35 \mathrm{~mm}\right)$

\section{Conclusion}

We investigated an active oxygen monitor, and focused specifically on atomic oxygen sensing using the QCM sensor with polymer detection layers. The QCM exhibited different frequency shifts owing to different reaction efficiencies toward atomic oxygen. In conclusion, we believe that we can choose different types of sensor to suit a wide range of situations, e.g., a low or high atomic oxygen density and/or a different active oxygen environment $\left(\mathrm{O}_{2}^{-}\right.$, ozone, $\mathrm{OH}$ radicals, etc.).

\section{Acknowledgements}

We thank Prof. Okamoto of Toyo University, for his technical advice concerning the ICP source and the plasma evaluation method.

We also thank Mr. F. Matsunaga and Mr. T. Takasaki of PEGASUS Software Inc., for supporting this work as regards the simulations.

\section{References}

1. K. Noda, R. Naganawa, Y. Kanekiyo, and H. Tao, Chemistry Letters. 32 (2003)1128-1129.
2. H. Matsumoto, M. Matsuoka, and K. Noda, Proceedings of the International Conference on Control and Automation Systems 2008 (ICCAS 2008), Seoul, Korea, October (2008) No. TEP-37. 3. H. Matsumoto, M. Matsuoka, and K. Noda, Chemistry Letters. 38 (2009) 216-217.

4. K. Yokota, S. Seikyu, M. Tagawa, and N. Ohmae, Proceedings of the 9th International Symposium on Material in a Space Environment, Noordwijk, Netherlands, June (2003), 265-272.

5. G. Z. Sauerbrey, Z. Phys.155 (1959) 206.

6. S. Iwamori, K. Kezuka, and A. Uemura, Mol. Cryst. Liq. Cryst. 471 (2007) 99-111.

7. S. Iwamori, N. Yanagawa, M. Sadamoto, R. Nara, and S. Nakahara, in: RECENT RESEARCH DEVELOPMENTS IN VACUUM SCIENCE \& TECHNOLOGY Vol. 4, S. G. Pandalai (Ed.), RESEARCH SIGNPOST (India) 49-60.

8. M. Yamamoto, S. Nakashima, H. Yamanishi, S. Ogata and Y. Shibutani, Jpn. J. Appl. Phys. 44 (2005) 8635-8639.

9. K. Okada, S. Komatsu and T. Ishigaki, Proceedings of the 8th International Symposium on Sputtering and Plasma Processes (ISSP-2005), Kanazawa, Japan (2005) 137-140.

10. Y. Miyagawa, H. Nakadate, M. Tanaka. M.

Ikeyama and S. Miyagawa, Surface Coating \& Technology 196 (2005) 155-161.

11. Y. Miyagawa, H. Nakadate, S. Nakano. and S. Miyagawa, Diamond and Related Materials 12 (2003) 927-980.

12. D. J. Economou, T. J. Bartel, R. S. Wise and D. P. Lymberopoulos, IEEE. Trans. Plasma Sci. 23 (1995) 581.

13. K. Nambu, T. Morimoto and M. Suetani, IEEE Trans. Plasma Sci. 27 (1999) 1379.

14. H. Takekida and K. Nambu, Jpn. J. Appl. Phys. 43 (2004) 3590.

15. Y. Ichikawa, A. Ichimura, J. Phys. Chem. Ref. Data 19 (1990) 637-651.

16. Russ R. Laher and Forrest R. Gilmore, J. Phys. Chem. Ref. Data 19 (1990) 277-305.

17. D. L. Albritton, At. Data Nucl. Data Tables 22 (1978) 1.

18. V. Vahedi and M. Surendra, Computer Physics Communications 87 (1995) 179.

19. Ronald E. Olson, James R. Peterson, and John Moseley, J. Chem. Phys. 53 (1970) 3391.

20. H. Nogami, G. Xu, S. T. Ko and O. Okada, Proceeding of the 6th International Display Workshop (IDW'99) (1999) 167.

21. Morton. A. Golub and T. Wydeven, Polymer Degradation and Stability. 22 (1988) 325-338. 